\title{
'Suddenly the first fifty years of my life made sense': experiences of older people with autism
}

\begin{tabular}{|c|l|}
\hline Journal: & Autism \\
\hline Manuscript ID & AUT-16-0133.R2 \\
\hline Manuscript Type: & Original Article \\
\hline Keywords: & Adults, Autism spectrum disorders, Diagnosis, Qualitative research \\
\hline Abstract: & $\begin{array}{l}\text { Research on the experience of growing older with autism is very limited. In } \\
\text { the present study, thirteen people with autism aged over 50 years } \\
\text { participated in semi-structured interviews about their experiences of } \\
\text { diagnosis, social support and getting older. Interviews were analysed using } \\
\text { thematic analysis. Three overarching themes were generated: difference, } \\
\text { life review, and longing for connection. Prior to diagnosis, individuals had } \\
\text { awareness of their difficulties, attributed these to intrinsic difference and } \\
\text { engaged in a deliberate process of reducing the visibility of this difference. } \\
\text { Diagnosis prompted a process of life review and externalisation, whereby } \\
\text { negative past experiences were reattributed to autism as opposed to the } \\
\text { self. Loneliness, isolation and yearning for interpersonal connection were } \\
\text { ubiquitous and longstanding. Autism support and social groups were highly } \\
\text { valued, offering opportunities for belonging, acceptance and social } \\
\text { comparison. Results highlight the similarity to younger age groups in terms } \\
\text { of lived experience and need for greater support, particularly with respect } \\
\text { to reducing isolation and improving access to diagnosis. }\end{array}$ \\
\hline \hline
\end{tabular}




\title{
'Suddenly the first fifty years of my life made sense': Experiences of older people with autism
}

\begin{abstract}
Research on the experience of growing older with autism is very limited. In the present study, thirteen people with autism aged over 50 years participated in semi-structured interviews about their experiences of diagnosis, social support and getting older. Interviews were analysed using thematic analysis. Three overarching themes were generated: difference, life review, and longing for connection. Prior to diagnosis, individuals had awareness of their difficulties, attributed these to intrinsic difference and engaged in a deliberate process of reducing the visibility of this difference. Diagnosis prompted a process of life review and externalisation, whereby negative past experiences were reattributed to autism as opposed to the self. Loneliness, isolation and yearning for interpersonal connection were ubiquitous and longstanding. Autism support and social groups were highly valued, offering opportunities for belonging, acceptance and social comparison. Results highlight the similarity to younger age groups in terms of lived experience and need for greater support, particularly with respect to reducing isolation and improving access to diagnosis.
\end{abstract}




\section{Keywords}

Autism spectrum disorders, adults, qualitative research, diagnosis

\section{Introduction}

Initially construed as a disorder of infancy and early childhood, the impairments of autism are now understood to be lifelong with similar prevalence rates across the lifespan (Baird et al., 2006; Brugha et al., 2011). Research has largely focused on autism in childhood, with research in older adulthood comparatively limited (Mukaetova-Ladinska et al., 2012). Given the ageing population in western countries, increasing diagnosis rates (King and Bearman, 2009), the current limited access to diagnostic services for adults (National Institute for Health and Care Excellence [NICE], 2012) and the high cost associated with the disorder (Järbrink and Knapp, 2001), investigating the experiences of and outcomes for older people with autism is of considerable importance.

Adults with autism are at higher risk of anxiety, depression and other psychiatric problems, with rates varying from 25 to over $75 \%$ depending on the population studied (Moss et al., 2015). Research has suggested that the later in life an individual receives their diagnosis, the greater the risk of experiencing psychiatric problems (Barnard et al., 2001). Individuals with autism also have poor outcomes with regards to living independently, with Hofvander et al. (2009) finding that only half of adults aged over 
23 years in their study were living independently. Howlin et al. (2004) found even poorer levels of independence in adults who were given a diagnosis of autism in childhood, reflecting the likelihood that individuals with more severe presentations reach clinical attention earlier in life (Happé and Charlton, 2012).

There is growing interest in investigating the experiences and views of adults with autism and qualitative approaches seem an important route to facilitating in-depth study of experience, emerging perspectives and the development of hypotheses (Bölte, 2014). To date, such research has mostly focused on young adults. Although some studies have included participants aged over 50 years (Griffith et al., 2012; Haertl et al., 2013; Hurlbutt and Chalmers, 2002, 2004; Müller et al., 2003, 2008; Robertson and Simmons, 2015), none have exclusively focussed on this group.

Qualitative studies of autism in adulthood have suggested a picture of enduring anxiety, depression, social isolation, communication difficulties and occupational underachievement, signifying how profoundly autism affects people's lives (Griffith et al., 2012; Hurlbutt and Chalmers, 2004; Jones et al., 2003; Müller et al., 2003, 2008; Portway and Johnson, 2005; Punshon et al., 2009). Furthermore, this research suggests that gaining a diagnosis of autism is often experienced as helpful in reducing blame, bringing a sense of relief, improving access to support services and facilitating understanding of previous life events (Huws and Jones, 2008; Punshon et al., 2009). 
The experiences of older adults might differ substantially from the experiences of a younger adult cohort. For instance, it is likely that high-functioning adults aged over 50 years would be without an autism diagnosis for much of their adult lives (Brugha et al. 2011), leaving them without a framework in which to make sense of difficult life experiences. There are also some specific challenges and life transitions that present in older age, such as retirement, ill health, bereavement, and loss of spouse or carer (Zaidi, 2014). Older cohorts may also differ from younger people in that the experience of negotiating, adapting to and managing sources of stress over the lifespan (Windle, 2011) might help people to come to terms and cope with the challenges inherent in the experience of autism.

Given these possible differences and the limited representation of older people in existing research, exploring the experiences of older people with autism is of importance in terms of understanding their particular needs and conceptualising potential avenues of support. Specifically, the objectives of the current research were to explore the lived experience of autism in later adulthood, what autism had meant for individuals' lives, and their perceptions regarding the helpfulness (or otherwise) of diagnosis. 


\section{Method}

\section{Methodological approach}

Thematic analysis was considered an appropriate analytic approach for this study as a theoretically-flexible method for identifying, analysing and interpreting patterns in qualitative data, particularly in under-researched areas (Braun et al., 2014).

Participants

Criteria for participation in the study included: (i) formal diagnosis of an autism spectrum disorder, (ii) minimum age of 50 years, (iii) ability to communicate verbally in English, (iv) no diagnosed intellectual disability, and (v) residency in the UK. Regarding recruitment, nine older individuals with autism diagnoses received an information leaflet on the study via a National Health Service (NHS) adult autism diagnostic service, four of whom contacted the first author and participated. The remaining nine participants were recruited via autism support and social groups in London; it was not possible to verify how many individuals received information at these groups and declined to participate. Thirteen individuals therefore participated in total; all categorised themselves as of White ethnicity and all but two participants were British. All were diagnosed with autism in adulthood, with formal diagnosis obtained an average of six years prior to participating in the study. Recruitment ceased when there were no further emergent patterns in the data. 
Diagnostic status for the four participants from the diagnostic clinic was verified according to ICD-10 criteria (World Health Organisation, 1993), with one other participant able to provide a diagnostic report. Diagnostic status of the remaining eight individuals was based on self-report, with participants providing the name of their diagnosing clinician and service. All participants completed the Autism Spectrum Quotient (AQ; Baron-Cohen et al., 2001), a 50-item self-report autism screening tool, as an additional diagnostic check. Three participants did not score above the clinical threshold of 26, which is in line with reported discriminant validity (Woodbury-Smith et al., 2005). This study constitutes an initial exploration in an under-researched area and proposed to capture a broad range of experiences; consequently these individuals were included to capture the heterogeneity of presentations across the autism spectrum.

All but three participants reported experiencing at least one mental health problem in their lives; the most commonly reported were depression and anxiety. Participants completed the Hospital Anxiety and Depression Scale (HADS; Zigmond and Snaith, 1983), providing subscale scores for depression and anxiety. Scores indicated that three participants had symptoms suggestive of at least mild depression, and all but one had symptoms of at least mild anxiety (see Table 1). 
Procedure

Ethical approval for this study was granted by the university Research Ethics Committee (reference: 5446/001). Written informed consent was obtained for each participant. Demographic information was collected prior to the interview, which was audio-recorded and lasted an average of 1 hour 20 minutes (range: 58 to 93 minutes).

A semi-structured interview schedule was developed based on previous qualitative research on autism in adulthood and refined with input from an older person with autism recruited from a local autism support group (see Appendix). The schedule consisted of open-ended questions worded in a conversational style. It began with broad questions regarding how participants had become aware of autism, before exploring their decision to initiate the diagnostic process and what the diagnosis meant for them. It also explored social support, how participants' lives had changed over the decades, and how they imagined their lives in the coming years.

\section{Data analysis}

The interviews were transcribed in full by the first author and identifying information removed. The data were analysed according to Braun and Clarke's (2006) approach to thematic analysis. The primary researcher read and re-read the whole data set, noting any initial observations in the margins. She then methodologically coded the data, applying succinct labels to key ideas in the data which were then studied for wider 
patterns of meaning (overarching themes and constituent subthemes). Following a process of review, emerging themes were refined, described and named. Through this process, theme and subtheme definition and selection was not guided by interview questions asked, but through methodical coding and analysis of units of data.

The number of participants who mentioned information relevant to each subtheme was counted and themes were accordingly categorised as general, typical or variant to indicate theme prevalence, as recommended by Hill and colleagues (2005). Analysis incorporated both descriptive and interpretative components, with an attempt to theorise the significance of themes and their broader meanings and implications (Braun and Clarke, 2006). In qualitative analysis, credibility is used to measure quality (Elliot et al., 1999). In this case, credibility checks on codes and themes included a qualitative analyst independently coding four of the 13 transcripts and cross checking interpretation with the first author. Respondent validation was also sought, with the seven participants who responded all endorsing the overarching themes. 


\begin{tabular}{|c|c|c|c|c|c|c|c|c|c|c|c|}
\hline ID & Gender & Age & Diagnosis & AQ & $\begin{array}{l}\text { Years } \\
\text { since } \\
\text { diagnosis }\end{array}$ & $\begin{array}{l}\text { Relationship } \\
\text { status }\end{array}$ & Living status & $\begin{array}{l}\text { Employment status } \\
\text { (current/most recent } \\
\text { employment**) }\end{array}$ & $\begin{array}{l}\text { Educational level } \\
\text { attained }\end{array}$ & $\begin{array}{l}\text { Depression } \\
\text { (HADS) }\end{array}$ & $\begin{array}{l}\text { Anxiety } \\
\text { (HADS) }\end{array}$ \\
\hline $\mathrm{P} 1$ & Male & 64 & AS & 35 & 13 & Married & With spouse & $\begin{array}{l}\text { Part-time (business, media } \\
\text { and public service } \\
\text { professionals) }\end{array}$ & Bachelor's degree & 0 & 9 \\
\hline $\mathrm{P} 2$ & Female & 53 & HFA & 44 & 1 & Single & With sibling & Unemployed $>10$ years & Some university & 16 & 20 \\
\hline P3 & Male & 63 & HFA* & 17 & 16 & Single & $\begin{array}{l}\text { Supported } \\
\text { housing }\end{array}$ & Unemployed $>10$ years & $\begin{array}{l}\text { Some secondary } \\
\text { school }\end{array}$ & 3 & 14 \\
\hline P4 & Male & 56 & HFA* & 31 & 3 & Single & $\begin{array}{l}\text { Supported } \\
\text { housing }\end{array}$ & Unemployed $>10$ years & $\begin{array}{l}\text { Some secondary } \\
\text { school }\end{array}$ & 5 & 12 \\
\hline P5 & Female & 51 & $\mathrm{AS}^{*}$ & 34 & 1 & Single & Independent & $\begin{array}{l}\text { Part-time (administrative } \\
\text { occupations) }\end{array}$ & Bachelor's degree & 7 & 9 \\
\hline P6 & Male & 53 & AS & 19 & 3 & Single & $\begin{array}{l}\text { Private house } \\
\text { share }\end{array}$ & $\begin{array}{l}\text { Part-time (administrative } \\
\text { occupations) }\end{array}$ & Master's degree & 6 & 9 \\
\hline P7 & Male & 67 & HFA & 36 & 20 & Single & Independent & $\begin{array}{l}\text { Medically retired } * * * \\
\text { (administrative occupations) }\end{array}$ & $\begin{array}{l}\text { Some secondary } \\
\text { school }\end{array}$ & 6 & 11 \\
\hline P8 & Male & 71 & AS & 30 & 9 & Single & $\begin{array}{l}\text { Supported } \\
\text { housing }\end{array}$ & $\begin{array}{l}\text { Medically retired } \\
\text { (administrative occupations) }\end{array}$ & $\begin{array}{l}\text { Some secondary } \\
\text { school }\end{array}$ & 12 & 16 \\
\hline P9 & Male & 59 & $\mathrm{AS}^{*}$ & 36 & 1 & Cohabiting & With partner & $\begin{array}{l}\text { Medically retired (teaching } \\
\text { and educational professionals) }\end{array}$ & Bachelor's degree & 6 & 9 \\
\hline $\mathrm{P} 10$ & Male & 62 & HFA & 20 & 7 & Single & Independent & $\begin{array}{l}\text { Retired (textiles, printing and } \\
\text { other skilled trades) }\end{array}$ & Bachelor's degree & 0 & 0 \\
\hline P11 & Male & 61 & AS & 30 & 5 & Married & $\begin{array}{l}\text { With spouse, } \\
\text { children }\end{array}$ & $\begin{array}{l}\text { Fulltime (health and social } \\
\text { care associate professionals) }\end{array}$ & Bachelor's degree & 3 & 9 \\
\hline $\mathrm{P} 12$ & Female & 60 & AS & 45 & 3 & Divorced & $\begin{array}{l}\text { With child, } \\
\text { other family } \\
\text { members }\end{array}$ & $\begin{array}{l}\text { Fulltime (caring personal } \\
\text { service occupations) }\end{array}$ & $\begin{array}{l}\text { Some secondary } \\
\text { school }\end{array}$ & 9 & 17 \\
\hline P13 & Male & 65 & $\mathrm{AS}^{*}$ & 35 & 5 & Single & Independent & $\begin{array}{l}\text { Retired (unemployed }>10 \\
\text { years) }\end{array}$ & Bachelor's degree & 6 & 16 \\
\hline
\end{tabular}

Note $*=$ diagnostic status confirmed via NHS clinic or observation of diagnostic report; $* *=$ classified according to Office for National Statistics (2010) Occupation Coding Tool; ***medically retired = retired for stress or mental health reasons; AQ = Autism Spectrum Quotient (Baron-Cohen et al., 2001); AS = Asperger's syndrome; HADS classifications include mild (8-10), moderate (11-15) and severe $(\geq 16)$ (Snaith and Zigmond, 1994); HFA = high-functioning autism. 


\section{Results}

Analysis led to the generation of three overarching themes with nine constituent subthemes (see Table 2). Themes are described and illustrated with quotes in the section that follows. Data extracts are identified with participant number to show that themes are grounded in a wide variety of accounts. Filler and repeated words were removed from the extracts to enhance readability.

Table 2. Inductively developed themes, subthemes and prevalence rates.

\begin{tabular}{|c|c|}
\hline & Prevalence* $(\mathrm{n})$ \\
\hline \multicolumn{2}{|l|}{ Difference } \\
\hline Realisation of difference & Typical (11) \\
\hline Reducing outward difference & Variant (6) \\
\hline \multicolumn{2}{|l|}{ Life review } \\
\hline Understanding the past & General (13) \\
\hline Externalising autism & Typical (8) \\
\hline Self-acceptance & Variant (5) \\
\hline \multicolumn{2}{|l|}{ Longing for connection } \\
\hline Isolation and loneliness & Typical (9) \\
\hline Positive aspects of isolation & Variant (6) \\
\hline Reaching out (pre-diagnosis) & General (12) \\
\hline Reaching out (post-diagnosis) & Typical (10) \\
\hline
\end{tabular}

Theme 1: Difference

Prior to diagnosis and usually in adolescence and early adulthood, most participants went through a process of noticing and acknowledging their difference from peers. They then took steps to reduce the visibility of this difference to better 'fit in' socially. 
Realisation of difference. The gradual realisation of difference from peers typically began in childhood and intensified in adolescence, abetted by experiences of bullying in secondary school. This initial perception of difference was located internally.

The very first time I thought I was different, maybe in that way but I didn't know why, was when I was eight years old in '66. When they didn't put me up to the junior school from the primary school. And I thought, 'Oh, why are they doing that? What's wrong with me?' (P4)

Not all participants articulated that they had an early understanding that they were somehow different; some were aware that family members or teachers perceived them as different in the absence of their own conscious acknowledgement of difference.

Reducing outward difference. After conceptualising their difference, participants engaged in a process of studying their peers and imitating their social performance in order to reduce the visibility of their difference. Over time, learned social skills required less conscious application and became more habitual, enabling participants to ostensibly 'fit in', although an internal sense of difference persisted.

When you emulate things long enough they become a habit. So they become-you actually outwardly become exactly like everybody else. But you aren't. You never - you never forget. You're never not autistic. (P10) 


\begin{abstract}
While social skills were advantageous with respect to participating socially, interaction retained a performance quality and individuals still felt a distance between themselves and those with whom they interacted.

And I tried to smile like they smiled. And I think it helped me up to a point, to mix up with other people. But all the time I was hiding my true self. That was the problem. Inside I was feeling sort of bad. I wasn't really supposed to be like that. But it got me sort of with other people and that. (P12)
\end{abstract}

Theme 2: Life review

Participants described a process of reviewing the past in light of the autism diagnosis, followed by a process of externalising autism so that autism and the self were experienced as separate entities, with the aims of autism sometimes at odds with those of the self. Individuals applied their new knowledge of autism to improve social performance and participation.

Understanding the past. Participants described diagnosis as a lens through which to view aspects of the past that had hitherto been beyond explanation. Experiences such as bullying, academic underachievement, employment difficulties, persistent anxiety, and problems making and maintaining friendships and romantic relationships could be understood in a new light on the basis of diagnosis. One participant, who described how 
following diagnosis, 'suddenly the first fifty years of my life made sense,' described applying the diagnosis to his past experiences:

I mean, after the sort of diagnosis and learning what it was about, sort of almost every day I'd think of some incident way back: 'Ah yes, that happened because I was Asperger.' (P1)

In particular, the autism label enabled individuals to understand their social difficulties from a new perspective.

Well, for example, you have an explanation why is it [that] you find it difficult to meet people and relate to them. Once you have a few explanations, you find things smooth themselves out a bit. (P8)

Similarly, the diagnosis served to reduce shame around particular aspects of behaviour, unusual interests or perceived inadequacy with respect to some life goals.

Just that label, getting it last year, saying I've got a degree of autism. I knew it wouldn't be a cure or anything but it just explains those one or two things about your character. Like I've got this, like, secret world of animals and I have stories about them. And I used to be sort of - inside I used to feel ashamed about it. (P9)

For the majority of participants, diagnosis was benign or helpful. One participant, however, experienced her diagnosis and subsequent reviewing of the past as painful and isolating: 
So it was looking back and then suddenly realising there was this genetic connection and great feelings of inadequacy; that I must've been a really bad carer for my parents when they were terminally ill. And just having to, psychologically, on your own, reassess you whole life. And at the age of 53 it's going back a long way. (P2)

Externalising autism. The process of life review seemed to enable participants to consider autism as somewhat separate from their true selves. Autism provided a plausible explanation of why things went wrong or individuals failed to reach their full potential, meaning that difficulties could be attributed to autism rather than to the self. One man, who used the song lyric, 'sometimes my mind and I don't get along very well,' to understand the relationship between his autism and his sense of self, described the separateness of autism in the following way:

It's like a mind within a mind. Or a mind outside a mind that's kind of influencing your behaviour in a way that you don't want it to. (P13)

Similarly, another participant spoke of autism as an unpleasant but non-threatening behavioural feature, as opposed to a core aspect of the self:

It is a condition that is meant to make social relationships more difficult. And that could also bring you in awkward situations and things like that. And you happen not to worry about that too much and just see it as an autism thing. (P6) 
The attributing of negative experiences to autism allowed individuals to absolve themselves for what were previously perceived as personal shortcomings. The relationship between one's autism and wider society became the locus of potential distress, with society perceived as indifferent and unsympathetic towards difference, as exemplified in the following account of diagnosis:

It's a good thing to have happen. Because it makes you realise that all the problems you've had in the past you can put it down to one reason. And it's nothing to do with you yourself; it's because the other people don't understand why you're like that. And if they were to understand more why, they probably wouldn't carry on to you and harm you and upset you so much if they understood.

Externalising also facilitated a better understanding of autism, and individuals were sometimes able to use this awareness to capitalise on areas of strength or to minimise potential difficulties, such as special interests playing out in the social realm.

But I realise I am very passionate and I tend to go on about these things a bit. And other people don't really know what I'm talking about. And I'm just, if you like, at the moment, checking that in myself. (P13) 
Self-acceptance. The autism label facilitated a greater level of contemporary selfacceptance. By changing the standard by which they judged themselves, the diagnosis allowed participants to see their lives in a more tolerant and compassionate light.

I'm not pressurising myself to be like everyone else. You know, it doesn't matter if I like being on my own, living on my own. That's fine. It's 'cause I-you know, people with Asperger's are like that. So I can feel like I'm not somebody who's failed to have a relationship, failed to have children, failed to hold down a job or get to a higher position in a job. (P5)

Some individuals noted that the pressures of navigating the social and occupational world reduced with increasing age, which meant that older age may have been less stressful irrespective of the autism diagnosis.

When you're young you've got to make friends, you've got to find a partner, find a job and take exams and all this sort of thing. But when you're older you don't have those pressures, maybe. (P7)

\section{Theme 3: Longing for connection}

Most participants perceived themselves to be isolated and experienced a subjective sense of loneliness. However, being alone also allowed people the opportunity to pursue particular interests, which were highly valued. Participants made a conscious effort to 
socialise and acquire friends, particularly in early adulthood (pre-diagnosis) and later to meet other people with autism (post-diagnosis).

Isolation and loneliness. Isolation and loneliness seemed to be a defining feature of growing up and getting older with autism, which became no less distressing with advancing years.

See, I never had many friends when I was younger. So I think in a way it's sort of prepared me for being on my own. Although I don't like it much. I've never liked it. (P12)

In the context of limited social networks, people particularly focused on the lack of a romantic relationship, describing a sense of longing:

I think I'm a born loner, quite frankly. And even no matter... Maybe I'm not the kind of person to have a life. Oh, I'd love it, with a person that would understand me. (P4)

Loneliness was less prominent in the accounts of the three study participants who were married or cohabiting, suggesting that one close relationship went some way towards buffering the effects of social isolation. However, isolation and a sense of disconnection or being cut off from other people were still features of their experience: 
It's not to do with not having friends and stuff like that. It's to do with I just feel that I'm totally isolated in myself. I don't know what to say to anyone; I can't connect. (P11)

For most participants who were currently employed or had previously worked, employment and particularly the social aspects of work were experienced as stressful, as exemplified by the following quote:

Part of the reason I used to get anxious and depressed is 'cause I was making all these mistakes and socially [I'm] not very good, [I] find it difficult to talk to people especially in groups and things. Trouble, problems with work and forgetting things, making mistakes... And I'd just get really like, 'why am I so stupid? Why can't I do this?' (P5)

While a job afforded some degree of social contact in a structured context, the loss of that social contact and the narrowing of social opportunities following retirement were sometimes experienced as a relief:

But in the last five, ten years, as I've got old, I've found that I want to do less and less and less and less. And see less people. And do things which are a bit more comfortable. (P9) 
Positive aspects of isolation. Although most participants described themselves as socially isolated, aloneness was sometimes framed positively in that it allowed uninterrupted pursuit of hobbies and interests:

You know, where does lonely stop and isolated begin? I mean, I quite like my own company in some ways. Given that I'm quite hard-driven in my enthusiasm for certain things. (P13)

The solitary pursuit of interests allowed for immersion in particular activities and experiences of mastery and achievement. It also offered participants a place of safety, which was in contrast with their anxiety-laden experiences of trying to engage with the social world:

I'm interested in machines. I can master them, if you like. I can understand them. I can relate to them; I can relate to machines better than I can people. Machines do not put you down. They don't criticise you, they don't hurt you and they don't make you cry. Not generally. People do that. (P4)

Some participants described using interests as a deliberate tool to manage anxiety. In P5's case, she used particular activities to help her relax after work:

Sometimes I quite like to do ironing or hand sewing as a way of just doing something a bit repetitive. When I'm a bit stressed out. 
The potential of special interests to buffer distress for people with autism generally was acknowledged by some participants, and those who had secured employment in their field of interest were seen as especially lucky:

A lot of [people with] Asperger's don't suffer from chronic depression because they have a narrow field of interest and they might have a job in that field of interest. Especially males. (P2)

Reaching out (pre-diagnosis). Prior to diagnosis, many participants had made deliberate efforts to engage with people, usually in quite structured settings. They sometimes joined clubs related to interests and deliberately set about making friends, particularly in early adulthood. Structured activities or social gatherings with definite start and end points were preferred, serving to facilitate social interaction:

It was a structured thing and I felt rather more comfortable with that. So yeah, we sort of did - we were meeting around another activity. If I'm not focused on trying to be friendly with someone it's actually easier to be friendly with them. (P11)

Special interests allowed some participants access to a network of others who shared their interest:

I perhaps should say my interest in [vehicle] registrations means that I've got a network of friends throughout the country and beyond. And I've sort of regularly, 
you know - we don't meet up very often but we're regularly emailing each other. (P1)

Just one participant reported that his negative experiences of participating in the social world prompted him to withdraw:

So I got to a stage where I was so used to being mistaken by others, misinterpreted, misunderstood; I thought, well, sod it. If you're going to misunderstand me, I'm not going to even, going to... I just closed off later on in life. I just thought, sod it. (P4)

Reaching out (post-diagnosis). Post diagnosis, most participants had some involvement in autism groups or had occasion to meet other people with autism. For some, this was an attempt to increase their social engagement generally. For most, it was a deliberate effort to gather additional information about autism and how it applied to their lives. Meeting others with autism offered a sense of shared experience and understanding, which was lacking in participants' existing social networks. The importance of universality of experience and the sense of acceptance it endowed was mentioned in the accounts of seven participants, and can be seen in the following quotes:

You're accepted. You don't have to sort of hide anything. (P7)

The people, some of them are on my wavelength. (P3) 
Unlike universality and acceptance, emotional support or friendship-seeking seemed less important.

And I do feel like, yeah, well, they're in the same boat as me. Yeah, so, but I don't feel like - I don't socialise with them that much. I think a lot of people there don't, you know, don't go there to make friends. (P5)

Some individuals were shocked by the level of impairment exhibited by some people with autism, and strove to establish their place in the 'autism hierarchy'.

There were obviously people who were severely incapacitated by it. Who hardly spoke a word and were kind of - they had to have other people there with them as well. And on the other end - at the other end of the spectrum, I suppose - there were, there was a guy there [who] was doing a course at the university. And he seemed extremely lucid. So it's very difficult to see where I fit into. (P13)

This allowed some participants an opportunity to engage in a process of social comparison with other people with autism, which enabled them to notice particular strengths they possessed by comparison or to learn from other people. Social comparison and interpersonal learning were noted in interviews with five participants. For example, P6 described his discovery that a fellow group member struggled hugely with public transport:

And I don't have these difficulties at all. And I travel around London quite easily. That's what my passion is, to travel around London. 
Attending autism groups allowed certain aspects of experience to be normalised in the context of autism.

While we were just talking about various things, them saying, 'Oh, I have a problem with babies and noise.' And I used to be ashamed of that. (P9)

People were able to apply knowledge gained through interacting with others to their own circumstances:

They might come up with some problems they have - 'What do I do about this?' And I'm like, 'this is what you do.' And then, so I apply it to myself. That's what I ought to do about myself! (P8)

For two participants, both of whom were recruited via a small autism group in outer London, the discovery of hitherto unknown abilities, such as using metaphor, reading or creatively writing, was very powerful in their accounts:

Everything used to just go into a blur and I just couldn't concentrate. And she [group facilitator] said lots of people are like that with Asperger's. And the ones... She has a book club. And different books are given. And I've read aboutmust be about five or six books now! (P12)

The focus on something tangible (e.g., a book) facilitated the use of social skills in the absence of an overt focus on social skills: 
That's where we're focused on - it might be book club and we're focused on the book. But if you listen to the discussion on the book, it's very flowing and we can be really supportive. $(\mathrm{P} 11)$

\section{Discussion}

These findings illustrate the isolation, loneliness and longing for interpersonal connection that characterise navigating life with autism. Difficulties were maintained across the lifespan, echoing studies involving participants in younger and middle adulthood (Griffith et al., 2012; Hurlbutt and Chalmers, 2004; Jones et al., 2003; Müller et al., 2008; Portway and Johnson, 2005; Punshon et al., 2009). Participants working in a field that interested them or sustaining a romantic relationship seemed protected from some of the challenges of living with autism, and themes did not vary substantially as a function of participant age. Recognition of difference earlier in life, in the absence of anything tangible to which this could be attributed, was experienced as painful. Diagnosis helped to explain this difference and offered a new framework to understand past experiences. Autism-specific groups were highly valued, allowing for a sense of shared experience, acceptance and social comparison.

The results largely confirm the findings of previous research on the experiences of people with autism in earlier life, as opposed to generating themes that might pertain specifically to later life. For many participants, unemployment and living alone perhaps 
meant that life transitions typical of older age did not apply, and this might explain the lack of more stage-specific themes. This study confirms, in a new sample, what individuals with autism have previously spoken about in qualitative research, and therefore suggests that earlier research can be used to understand the experiences of people with autism in older age.

\section{Difference}

Participants demonstrated an awareness of difference when comparing themselves to 'neurotypical' peers as documented in previous research (Baldwin and Costley, 2016; Huws and Jones, 2013; Jones et al., 2003; Müller et al., 2008; Punshon et al., 2009; Williams, 2004). Furthermore, participants were found to engage in deliberate and effortful self-training in social interaction. This echoes previous research which found that individuals with autism made substantial efforts to compensate for autism by developing their social and self-awareness (Müller et al., 2008) or presenting a 'false self' to others (Griffith et al., 2012). This false self was 'conscious work' (Ryan and Räisänen, 2008), with social skills learned and intentionally deployed as appropriate, as opposed to internalised and automatic. For individuals who struggle to learn and apply social skills independently, group-based social skills interventions might be useful in improving social understanding and functioning (Spain and Blainey, 2015). 
Access to diagnosis

The process of reviewing one's life through the lens of the autism diagnosis was ubiquitous among participants. Painful aspects of past experience could now be explained using an autism framework, helping to integrate disparate experiences into a more coherent narrative, reduce self-blame and reattribute some responsibility for these experiences to the diagnosis. This is in line with previous work with adults (Punshon et al., 2009) and young people with autism (Huws and Jones, 2008). Furthermore, the tendency to externalise autism, separating it from the core or real self, has been documented in the accounts of individuals in middle adulthood (Griffith et al., 2012).

Participants in this study were without the autism diagnosis for most of their adult lives and thus possibly already had a stable sense of identity prior to diagnosis. This might explain their tendency towards externalisation as opposed to incorporating the autistic identity. The propensity towards externalisation might be cohort-specific or might change according to the growing influence of the 'neurodiversity' movement, whereby autism is conceptualised as a way of being within the spectrum of natural human diversity (Kenny et al., 2016; Robertson, 2010).

The process of externalising autism bears a striking similarity to the narrative therapy practice of 'externalising the problem' whereby individuals are helped to define their problems as separate from their identities, facilitating the interruption of the dominant, problem-saturated story (White and Epston, 1990). In the present study, 
knowledge regarding and externalisation of autism allowed for increased accessibility of strategies to improve social performance. Given the lack of empirically supported mental health treatments for people with autism (NICE, 2012), these findings suggest that externalisation might be a useful therapeutic intervention with this population. Additionally, the tendency towards greater self-acceptance following diagnosis suggests compassion-focused (Gilbert, 2009) or acceptance-based (Hayes et al., 1999) therapies could prove useful.

\section{Loneliness and isolation}

Findings of intense loneliness and a longing for connection and intimacy support the work of Haertl et al. (2013) and Müller et al. (2008). As with young adults (Punshon et al., 2009), accessing a network of others with autism was important for participants, allowing them to feel understood and accepted. This protective value of group identity has been similarly highlighted in research with other stigmatised groups (e.g., Crabtree et al., 2010).

The benefits of downward comparison afforded by support group membership are in line with the accounts of younger people with autism (Huws and Jones, 2013). Perhaps, as suggested by Crocker and Major (1989), affiliation with others with a shared diagnosis provides opportunities for social comparisons with the in-group as opposed to the relatively advantaged out-group, thereby protecting self-esteem. A more 
detailed exploration is required to understand the mechanisms by which people with autism use social support networks to protect their sense of self and preserve selfesteem.

The findings suggest that information on local autism support groups and networks should be routinely provided to individuals following diagnosis. These are likely to go some way towards alleviating social isolation and loneliness, and target the need for information and access to others with similar experiences. Online autism groups might also be useful in improving access to others with autism (Bagatell, 2010; Ryan and Räisänen, 2008), which might provide the added benefit of reducing the social demands of face-to-face communication.

\section{Limitations}

Although the AQ (Baron-Cohen et al, 2001) was used to enhance confidence in diagnostic status, the lack of verified diagnoses for a majority of participants is acknowledged as a limitation. However, the experiences described by individuals recruited via support and social groups were not noticeably different to the experiences of people recruited via the NHS clinic whose diagnoses were confirmed, and indeed most of those recruited via the clinic also attended the autism groups.

While generalisability is not the aim of qualitative research, there are some potential limitations regarding the extent to which the experiences of these 13 
participants might apply to other older people with autism. In particular, individuals with comorbid intellectual disability were excluded from participation and no participants received their diagnosis in childhood, so transferability to these groups may be limited. Regarding gender representativeness, the gender ratio is similar to that reported in previous studies of high-functioning adults with autism (e.g., Baron-Cohen et al., 1997).

The recruitment procedure partly relied on local autism support and social groups, which may have biased recruitment towards those who were more accepting of their diagnosis and committed to it. Similarly, the study procedure itself may have biased selection in favour of those more willing to engage socially. Given the array of social communication differences experienced by individuals with autism, there are inherent challenges to using a research methodology that relies on interviews, especially the semi-structured, open-ended and conversational approach taken in the current study. At times, interviews moved onto topics of special interest or detailed discussion of specific past experiences, and consequently the quantity of interview data relevant to the research topic varied between individuals. It is possible that ideas from individuals more able to access thoughts pertaining directly to the research questions were overrepresented during coding and theme development. Collecting data through writing or via computer might be a useful avenue for future research. 
The degree to which the age-related preference for positive over negative information (Mather and Carstensen, 2005) or possible autism-related deficits in episodic memory (Bowler et al., 2000) might have influenced data is unknown. Interview data tended to focus on the recent or distant past, while data were not particularly rich with respect to the intermediate decades of life or consideration of the future. The contemporary focus might be a product of the recency of diagnosis for many participants. The focus on the second and third decades of life possibly reflects their importance in terms of psychosocial developmental tasks, particularly identity formation and the formation of intimate relationships (Erikson, 1959). For most participants, the absence of a partner and lengthy periods of unemployment perhaps meant that some life cycle transitions simply did not apply, and that life may not have changed remarkably over the middle adulthood years.

\section{Conclusion}

The present study is the first to qualitatively investigate the experiences of adults with autism aged 50 years and beyond. The results are strikingly similar to previous qualitative studies of autism in younger adulthood, suggesting that the challenges faced by individuals with autism are perpetuated across the lifespan and that research with a younger group may be useful in understanding an older group. Findings highlight the importance of reducing isolation and improving access to diagnosis. 


\section{Acknowledgements}

We would like to thank all the participants who took the time to share their experiences as part of this study and those in the autism support and social groups who supported recruitment. We are also grateful to John Harrison for helping develop the interview schedule, and Catherine Vahey for coding a subset of transcripts.

\section{Funding}

This research received no specific grant from any funding agency in the public, commercial, or not-for-profit sectors.

\section{References}

Bagatell N (2010) From cure to community: transforming notions of autism. Journal of the Society for Psychological Anthropology 38(1): 33-55.

Baird G, Simonoff E, Pickles A, et al. (2006) Prevalence of disorders of the autism spectrum in a population cohort of children in South Thames: the Special Needs and Autism Project (SNAP). The Lancet 368(9531): 210-215.

Baldwin S and Costley D (2016) The experiences and needs of female adults with highfunctioning autism spectrum disorder. Autism 20(4): 483-495.

Barnard J, Harvey V, Potter D, et al. (2001) Ignored or ineligible? The reality for adults with autism spectrum disorders. London: The National Autistic Society. 
Baron-Cohen S, Jolliffe T, Mortimore C, et al. (1997) Another advanced test of theory of mind: evidence from very high functioning adults with autism or Asperger syndrome. Journal of Child Psychology and Psychiatry 38(7): 813-822.

Baron-Cohen S, Wheelwright S, Skinner R, et al. (2001) The Autism-Spectrum Quotient (AQ): evidence from Asperger syndrome/high-functioning autism, males and females, scientists and mathematicians. Journal of Autism and Developmental Disorders 31(1): 5-17.

Bölte S (2014) The power of words: is qualitative research as important as quantitative research in the study of autism? Autism 18(2): 67-68.

Bowler DM, Gardiner JM and Grice SJ (2000) Episodic memory and remembering in adults with Asperger syndrome. Journal of Autism and Developmental Disorders 30(4): 295304.

Braun V and Clarke V (2006) Using thematic analysis in psychology. Qualitative Research in Psychology 3(2): 77-101.

Braun V, Clarke V and Terry G (2014) Thematic analysis. In: Rohleder P and Lyons AC (eds) Qualitative Research in Clinical and Health Psychology. Basingstoke: Palgrave Macmillan, pp. 95-113.

Brugha TS, McManus S, Bankart J, et al. (2011) Epidemiology of autism spectrum disorders in adults in the community in England. Archives of General Psychiatry 68(5): 459-465. 
Crabtree JW, Haslam SA, Postmes T, et al. (2010) Mental health support groups, stigma, and self-esteem: positive and negative implications of group identification. Journal of Social Issues 66(3): 553-569.

Crocker J and Major B (1989) Social stigma and self-esteem: the self-protective properties of stigma. Psychological Review 96(4): 608-630.

Elliott R, Fischer CT and Rennie DL (1999) Evolving guidelines for publication of qualitative research studies in psychology and related fields. British Journal of Clinical Psychology 38(3): 215-229.

Erikson EH (1959) Identity and the Life Cycle. New York: International Universities Press.

Gilbert P (2009) Introducing compassion-focused therapy. Advances in Psychiatric Treatment 15(3): 199-208.

Griffith GM, Totsika V, Nash S, et al. (2012) 'I just don't fit anywhere': support experiences and future support needs of individuals with Asperger syndrome in middle adulthood. Autism 16(5): 532-546.

Haertl K, Callahan D, Markovics J, et al. (2013) Perspectives of adults living with autism spectrum disorder: psychosocial and occupational implications. Occupational Therapy in Mental Health 29(1): 27-41.

Happé F and Charlton RA (2012) Aging in autism spectrum disorders: a mini-review. Gerontology 58(1): 70-78. 
Hayes SC, Strosahl K and Wilson KG (1999) Acceptance and Commitment Therapy: An Experiential Approach to Behavior Change. New York: Guilford Press.

Hill CE, Knox S, Thompson BJ, et al. (2005) Consensual qualitative research: an update. Journal of Counselling Psychology 52(2): 196-205.

Hofvander B, Delorme R, Chaste P, et al. (2009) Psychiatric and psychosocial problems in adults with normal-intelligence autism spectrum disorders. BMC Psychiatry 9(35): 1-9.

Howlin P, Goode S, Hutton J, et al. (2004) Adult outcome for children with autism. Journal of Child Psychology and Psychiatry 45(2): 212-229.

Hurlbutt K and Chalmers L (2002) Adults with autism speak out: perceptions of their life experiences. Focus on Autism and Other Developmental Disabilities 17(2): 103-111.

Hurlbutt K and Chalmers L (2004) Employment and adults with Asperger syndrome. Focus on Autism and Other Developmental Disabilities 19(4): 215-222.

Huws JC and Jones RSP (2008) Diagnosis, disclosure, and having autism: an interpretative phenomenological analysis of the perceptions of young people with autism. Journal of Intellectual and Developmental Disability 33(2): 99-107.

Huws JC and Jones RSP (2013) 'I'm really glad this is developmental': autism and social comparisons - an interpretative phenomenological analysis. Autism 19(1): 84-90.

Järbrink K and Knapp M (2001) The economic impact of autism in Britain. Autism 5(1): 7-22. 
Jones RSP, Quigney C and Huws JC (2003) First-hand accounts of sensory perceptual experiences in autism: a qualitative analysis. Journal of Intellectual \& Developmental Disability 28(2): 112-121.

Kenny L, Hattersley C, Molins B, et al. (2016) Which terms should be used to describe autism? Perspectives from the UK autism community. Autism 20(4): 442-462.

King M and Bearman P (2009) Diagnostic change and the increased prevalence of autism. International Journal of Epidemiology 38(5): 1224-1234.

Mather M and Carstensen LL (2005) Aging and motivated cognition: the positivity effect in attention and memory. Trends in Cognitive Sciences 9(10): 496-502.

Moss P, Howlin P, Savage S, et al. (2015) Self and informant reports of mental health difficulties among adults with autism findings from a long-term follow-up study. Autism 19(7): 832-841.

Mukaetova-Ladinska EB, Perry E, Baron M, et al. (2012) Ageing in people with autistic spectrum disorder. International Journal of Geriatric Psychiatry 27(2): 109-118.

Müller E, Schuler A, Burton BA, et al. (2003) Meeting the vocational support needs of individuals with Asperger syndrome and other autism spectrum disabilities. Journal of Vocational Rehabilitation 18(3): 163-175.

Müller E, Schuler A and Yates GB (2008) Social challenges and supports from the perspective of individuals with Asperger syndrome and other autism spectrum disabilities. Autism 12(2): 173-190. 
National Institute for Health and Care Excellence (NICE) (2012) Autism in Adults: Diagnosis and Management (CG142). London: NICE.

Office for National Statistics (2010) ONS Occupation Coding Tool. Available at: www.neighbourhood.statistics.gov.uk/HTMLDocs/dev3/ONS_SOC_occupation_coding _tool.html

Portway SM and Johnson B (2005) Do you know I have Asperger's syndrome? Risks of a nonobvious disability. Health, Risk \& Society 7(1): 73-83.

Punshon C, Skirrow P and Murphy G (2009) The 'not guilty verdict': psychological reactions to a diagnosis of Asperger syndrome in adulthood. Autism 13(3): 265-283.

Robertson AE and Simmons DR (2015) The sensory experiences of adults with autism spectrum disorder: a qualitative analysis. Perception 44(5): 569-586.

Robertson SM (2010) Neurodiversity, quality of life, and autistic adults: shifting research and professional focuses onto real life challenges. Disability Studies Quarterly 30(1). Available at: http://www.dsq-sds.org/article/view/1069/1234

Ryan S and Räisänen U (2008) "It's like you are just a spectator in this thing": Experiencing social life the 'aspie' way. Emotion, Space and Society 1(2): 135-143.

Snaith RP and Zigmond AS (1994) The Hospital Anxiety and Depression Scale. Windsor: NFER-Nelson.

Spain D and Blainey SH (2015) Group social skills interventions for adults with highfunctioning autism spectrum disorders: a systematic review. Autism 19(7): 874-886. 
White M and Epston D (1990) Narrative Means to Therapeutic Ends. New York: WW Norton. Williams E (2004) Who really needs a ‘theory' of mind? An interpretative phenomenological analysis of the autobiographical writings of ten high-functioning individuals with an autism spectrum disorder. Theory \& Psychology 14(5): 704-724.

Windle G (2011) What is resilience? A review and concept analysis. Reviews in Clinical Gerontology 21(2): 152-169.

Woodbury-Smith MR, Robinson J, Wheelwright S, et al. (2005) Screening adults for Asperger syndrome using the AQ: a preliminary study of its diagnostic validity in clinical practice. Journal of Autism and Developmental Disorders 35(3): 331-335.

World Health Organization (1993) The ICD-10 Classification of Mental and Behavioural Disorders: Diagnostic Criteria for Research. Geneva: World Health Organisation.

Zaidi A (2014) Life Cycle Transitions and Vulnerabilities in Old Age: A Review. Occasional Paper. New York: UNDP Human Development Report Office. Available at: http://hdr.undp.org/sites/default/files/hdr_2014_zaidi_final.pdf

Zigmond AS and Snaith RP (1983) The hospital anxiety and depression scale. Acta Psychiatrica Scandinavica 67(6): 361-370. 


\section{Appendix}

Semi-structured interview schedule

Where did you first hear about autism?

When did you start to think that autism might apply to you? (What made somebody else think that it might apply to you? What made you/them think this?)

What prompted you to seek a diagnosis?

Did finding out that you had autism change how you saw/understood yourself? Did it change how others understood you?

Would you say that your autism symptoms have changed over time?

What kind of things do you do to help cope with autism traits?

To whom do you turn for support (practical, emotional, informational)?

How would you describe the quality of your relationships with other people? (Prompts:

closest relationship, satisfaction, specific challenges, frequency/nature of contact, loneliness).

If attending community-based autism group/accessing online support, what prompted you to do so?

What transitions/changes are happening for you at the moment (e.g., retirement, loss of parents/family support, poor health)? How are you managing these?

How are things the same/different now compared to your 20 s, 30 s, etc.?

What are your hopes/worries for the future? 
1

2

3

4

5

6

7

8

9

10

11

12

13

14

15

16

17

18

19

20

21

22

23

24

25

26

27

28

29

30

31

32

33

34

35

36

37

38

39

40

41

42

43

44

45

46

47

48

49

50

51

52

53

54

55

56

57

58

59

60
What advice would you give to somebody who has been recently diagnosed with autism?
39

http://mc.manuscriptcentral.com/autism 